\title{
Association between restless leg syndrom and slow coronary flow
}

\author{
İsmail Erden, Emine Çakcak Erden¹, Hacer Durmuş², Hakan Tıbıllı, Mustafa Tabakçı, Mehmet Emin Kalkan, \\ Yasin Türker ${ }^{3}$, Mustafa Akçakoyun \\ Clinic of Cardiology, Kartal Koşuyolu Heart and Research Hospital; İstanbul-Turkey \\ ${ }^{1}$ Clinic of Cardiology, Emsey Hospital; İstanbul-Turkey \\ ${ }^{2}$ Department of Neurology, İstanbul Faculty of Medicine, İstanbul University; İstanbul-Turkey \\ ${ }^{3}$ Department of Cardiology, Düzce Faculty of Medicine, Düzce University; Düzce-Turkey
}

\section{ABSTRACT}

Objective: Restless legs syndrome (RLS) is a common sleep disorder in which patients feel unpleasent leg sensations and urge to move the legs during rest, especially at night, and symptoms are improved by leg movement. Prior studies analyzing the associations between cardiovascular disease and restless legs syndrome has shown controversial results. The goal of the study was to estimate the relationship between restless legs syndrome and slow coronary flow (SCF).

Methods: The present study was cross-sectional and observational and consists of 176 individuals who underwent coronary angiography and had angiographically normal coronary arteries of varying coronary flow rates. The study included 86 patients with isolated SCF and 90 control participants with normal coronary flow (NCF). RLS was assessed the day after the coronry flow was evaluated, using a self-administered questionnaire based on the International Restless Legs Study Group criteria. The following question was asked: “Do you have unpleasant leg sensations (like crawling, paraesthesia, or pain) combined with motor restlessness and an urge to move?" The possible responses were as follows: no, less than once/month, 2-4 times/month, 5-14 times/month, and 15 or more times per month. Those who answered that they had these feelings were asked the following two more questions: 1) "Do these symptoms occur only at rest and does moving improve them?" and 2) "Are these symptoms worsen in the evening/at night compared with the morning?" RLS is considered to be probable if the participant has answered "yes" for all three of the above questions, and has a frequency of $\geq 5$ times/month. Student's t-test, Mann-Whitney U test, multiple logistic regression analysis were used for statistical analysis.

Results: The prevalence of restless legs syndrome was $48(27 \%)$ and increased significantly with age. Patients with SCF have more likely had RLS than the control group $(\mathrm{p}<0.001)$. The age-adjusted prevalence odds of SCF were 3.11 times higher $(95 \% \mathrm{Cl}$ : $1.54-6.29 ; \mathrm{P}<0.001)$ among patients with RLS symptoms. Significant associations between RLS and SCF did not materially change after further adjustment for other potential covariates, such as sex, BMI, BMI squared, smoking.

Conclusion: Our study concluded that there is a strong link between SCF and RLS (Anadolu Kardiyol Derg 2014; 14: 612-6)

Key words: restless legs syndrome, slow coronary flow

\section{Introduction}

Restless legs syndrome (RLS) is a common, yet underestimated sensory motor disorder characterized by intense, unpleasant leg sensations and an irresistible urge to move the legs (1). The symptoms of RLS can impair sleep onset, sleep maintenance and causes daytime fatigue, resulting loss in cognitive ability, productivity and quality of life (1-3).

Prior studies analyzing the associations between cardiovascular disease and restless legs syndrome has found controversial results (4). Tambe et al. (5) found that RLS is associated with prevalent coronary artery disease and cardiovascular disease.
This association appears stronger in those with greater frequency or severity of RLS symptoms. But, Szentkirályi et al. (6) showed that the presence of RLS is not a significant risk factor of cardiovascular morbidity.

Sympathetic overactivity leading to vasoconstriction has been postulated. However, the mechanisms linking RLS and cardiovascular diseases are unknown.

Slow coronary flow is slow progression of contrast agent through the coronary arteries in the absence of stenosis in epicardial coronary vessels (5). Endothelial dysfunction and diffuse atherosclerosis have been proposed for the etiology of SCF (7). Previous studies have suggested micro and macro vascular

Address for Correspondence: Dr. İsmail Erden, Kartal Koşuyolu Yüksek Ihtisas Eğitim Araştırma Hastanesi Kardiyoloji Kliniği; İstanbul-Türkiye Phone: +90 3805421392 Fax: +90 3805421387 E-mail: iserdemus@yahoo.com Accepted Date: 05.11.2013 Available Online Date: 14.02.2014 
endothelial dysfunction, diffuse atherosclerosis, abnormally high small-vessel resistance and increased microvascular tone as the cause of SCF (8). The clinical implications are significant, with over $80 \%$ of patients experiencing recurrent chest pain, resulting in considerable impairment in quality of life. However, current clinical practice tends to underestimate the impact of SCF due to the yet unknown mechanisms, its relative rarity, and the subsequent difficulties in conducting randomized trials to evaluate different treatment options.

The aim of the present study was to assess the relationship between primary RLS and SCF.

\section{Methods}

\section{Patient selection}

This study included 86 patients ( 50 men, 36 women; mean age $47.7 \pm 5.0$ years) with SCF, and an age and gender matched control group was composed of 90 patients with normal coronary arteries and normal coronary flow on coronary angiography (47 men, 43 woman, mean age $46.6 \pm 4.2$ years). The local Ethics Committee approved the study and patients written informed consent obtained according to the Declaration of Helsinki. Diagnosis of SCF was based on TIMI frame count (TFC) and the presence of normal coronary arteries without luminal irregularities. All the patients had stenotic lesions of lower than $20 \%$ and normal coronary flow. In all groups, the indication for coronary angiography was determined either the presence of typical angina or positive or suspicious results obtained from noninvasive screening tests for myocardial ischemia.

All known causes for SCF other then RLS were excluded from study: Prior myocardial infarction, valvular heart disease, heart failure, peripheral vascular disease, coronary artery ectasia, diabetes mellitus, hypertension, renal and hepatic dysfunction, hematological disorders, history of malignancy, acute or chronic infection and stroke. Patient with secondary hypertension, coronary artery disease, cardiac failure, obstructive sleep apnea syndrome, psychiatric diseases, diabetes mellitus, iron deficiency (confirmed by a low serum ferritin (a cut-off value of $<50 \mu \mathrm{mg} / \mathrm{L}$ ), red cell microcytosis or hypochromia in the absence of haemoglobinopathies) (9), hypothyroidism, hyperthyroidism, night-time workers, BMl $>30 \mathrm{~kg} / \mathrm{m}^{2}$, patients who were using medications including major psychotropic, antidepressant and narcotics agents, oral steroids or daily NSAIDS, women experiencing menopause related symptoms, renal and hepatic dysfunction or any history of systemic disease, which could cause secondary RLS also excluded from our study.

\section{Coronary angiography and documentation of TIMI frame count.}

Patients underwent selective coronary angiography using the standard Judkins technique (10). Coronary arteries were visualized in left and right oblique planes, and cranial and caudal angles. Left ventriculography was performed in left and right anterior oblique views. Injection of contrast medium (lopromide, Ultravist-370; Schering AG, Berlin, Germany) was carried out by an automatic injector at a speed of 3-4 $\mathrm{mL} / \mathrm{sec}$ for the left coronary artery and $2-3 \mathrm{~mL} / \mathrm{sec}$ for the right coronary artery. Arteriographies were recorded at a speed of 25 frames/sec. Coronary flow was quantified objectively by two independent observers who were blinded to the clinical details of the individual participants, using the corrected TFC method. The first frame was defined by a column of contrast extending across more than $70 \%$ of the arterial lumen in an anterograde motion (8). Since the normal frame counts for the left anterior descending (LAD) coronary artery are 1.7 times greater than the mean for the left circumflex coronary artery and the right coronary artery (10) the TFCs for the LAD were divided by 1.7 to derive the corrected TFC as described earlier (11).

\section{Definition of slow coronary flow}

All participants with a corrected TFC greater than two standard deviations from the normal range reported for the particular vessel were accepted as having SCF while those whose corrected TFC fell within two standard deviations were considered to have normal coronary flow (8). After assessment of coronary flow using the corrected TFC method, the mean corrected TFC was derived by arithmetic mean of the sum of the corrected TFCs for the LAD, left circumflex coronary artery, and right coronary artery. Intra- and interobserver variabilities for TFC were 0.97 and 0.94 , respectively.

\section{Assessment of RLS}

After coronary angiography, socio-demographic and clinical data were obtained by an interview, using a standardized questionnaire applied by three previously trained individuals. Diagnostic criteria for RLS were based on answers from the International Restless Legs Syndrome Study Group Questionnaire (IRLS) (11). The following question was asked by interview using a standardized questionnaire applied by three previously trained individuals the day after the coronary flow was evaluated: "Do you have unpleasant leg sensations (like crawling, paraesthesia, or pain) combined with motor restlessness and an urge to move?" The possible responses were as follows: no, less than once/month, 2-4 times/month, 5-14 times/month, and 15 or more times per month. Those who answered that they had these feelings were asked the following two more questions: 1) "Do these symptoms occur only at rest and does moving improve them?" and 2) "Are these symptoms worsen in the evening/at night compared with the morning?" RLS is considered to be probable if the participant has answered "yes" for all three of the above questions, and has a frequency of $\geq 5$ times/month.

\section{Statistical analysis}

We used SPSS 13.0 (SPSS Inc, Chicago, IL, USA) program for statistical analysis. Quantitative variables calculated as arithmetical mean \pm standard deviation and categorical variables 
denoted as \%. Student's t-test was used to compare normally distributed continuous variables and the Mann-Whitney $U$ test for variables without normal distribution. The chi-square test was used to compare categorical variables. One-way analysis of variance is used for means in order to compare study groups. $\mathrm{P}<0.05$ is accepted for statistical significance. Variables, found to have significant differences in univariate analysis were incorporated in a multiple logistic regression model for determining the predictors of restless legs syndrome.

\section{Results}

Clinical and demographical features of the eighty- six patients with SCF are shown in Table 1. Mean age at the coronary angiography were $47.7 \pm 5.03$ (between $37-56$ years). Fifty of them were male and 36 were female. Patients with SCF have more likely had RLS than the control group $(p<0.001)$.

Restless legs syndrome were present in $48(27 \%)$. Patients with RLS were older than those without RLS $(50.6 \pm 3.8$ years versus $45.8 \pm 4.2$ years; $p<0.001$ ) (Table 2 ).

The age-adjusted prevalence odds of SCF were 3.11 times higher (95\% Cl: 1.54-6.29; $p<0.001)$ among patients with RLS symptoms (Table 3). Significant associations between RLS and SCF did not materially change after further adjustment for other potential covariates, such as sex, BMI, BMI squared, smoking.

\section{Discussion}

Our data suggest a strong relationship between RLS and SCF and demonstrate increased prevalence of SCF among patients with RLS. The association seems to be independent of age, gender, BMI and smoking status. To our knowledge, present study is the first study that provided data regarding the association between SCF and RLS; both conditions might be associated with a common cause, such as autonomic over-activity or might trigger each other.

Restless legs syndrome, is very common movement disorder, which could cause major disruption of sleep and significant impairments in quality of life. Pathophysiology of the disease had not been fully elucidated yet, but most of the research is focused on the dopamine and iron system. It has been previously noticed that there is a close relation between RLS and vascular diseases which may caused by autonomic over-activity.

Most individuals with clinically significant RLS (88-94\%) report sleep disturbances; the night-time discomfort of RLS deters one's attempt to fall asleep, thus delaying sleep onset, and also causes frequent awakenings during intended nocturnal sleep (12). One potential pathophysiological mechanism supporting such an increase of blood pressure (BP) is that stress activates the autonomic nervous system and synthesis of catecholamines (13). Another mechanism, a change in the set point of arterial baroreflex function in response to the stress, has been proposed by Ogawa et al. (14). Because RLS gives rise to a
Table 1. Comparison of clinical and demographical features of patients with SCF and control group with normal coronary artery

\begin{tabular}{|l|c|c|c|}
\hline & $\begin{array}{c}\text { SCF } \\
\text { (n=86) }\end{array}$ & $\begin{array}{c}\text { Control- NCA } \\
\text { (n=90) }\end{array}$ & $\boldsymbol{P}$ \\
\hline $\begin{array}{l}\text { Mean age at the time of } \\
\text { the coronary angiography } \\
\text { (years } \pm \text { SD) }\end{array}$ & $\begin{array}{c}47.7 \pm 5.03 \\
\text { (between } 37-56 \\
\text { years) }\end{array}$ & $\begin{array}{c}46.6 \pm 4.2 \\
\text { (between 39-57) }\end{array}$ & $0.122^{* *}$ \\
\hline Male/Female, $\mathrm{n}, \%$ & $\begin{array}{c}50 / 36 \\
(58 / 42 \%)\end{array}$ & $\begin{array}{c}43 / 47 \\
(47.8 / 52.2 \%)\end{array}$ & $0.178^{*}$ \\
\hline BMl, kg/m & $27.2 \pm 3.8$ & $27.1 \pm 3.1$ & $0.690^{* *}$ \\
\hline Cigarette smoking, $\mathrm{n}, \%$ & $28(33)$ & $20(22)$ & $0.691^{*}$ \\
\hline Total cholesterol, $\mathrm{mg} / \mathrm{dL}$ & $192.9 \pm 38.8$ & $189.4 \pm 40.4$ & $0.628^{* *}$ \\
\hline LDL cholesterol, $\mathrm{mg} / \mathrm{dL}$ & $113.5 \pm 34.4$ & $110.8 \pm 32.3$ & $0.641^{* *}$ \\
\hline Hemoglobin, $\mathrm{mg} / \mathrm{dL}$ & $13.5 \pm 1.3$ & $13.3 \pm 1.6$ & $0.317^{* *}$ \\
\hline Glucose, mg/dL & $98.3 \pm 12.6$ & $99.7 \pm 11.4$ & $0.412^{* *}$ \\
\hline Creatinine, $\mathrm{mg} / \mathrm{dL}$ & $0.79 \pm 0.17$ & $0.77 \pm 0.15$ & $0.512^{* *}$ \\
\hline RLS, $\mathrm{n}$ (\%) & $33(38)$ & $15(17)$ & $<0.001$ \\
\hline
\end{tabular}

$\mathrm{BMI}$ - body-mass index; NCA - normal coronary artery; NS-not significant ( $\mathrm{p} \geq 0.05)$; SCFslow coronary flow; RLS - restless legs syndrome; SD-standard deviation. *Pearson chisquare, ${ }^{* *}$ Independent samples t-test. Minimum and maximum values are indicated in brackets where applicable

Table 2. Demographic and clinical features of the patients with RLS versus without RLS

\begin{tabular}{|c|c|c|c|}
\hline & $\begin{array}{l}\text { RLS (+) } \\
(n=48)\end{array}$ & $\begin{array}{l}\text { RLS (-) } \\
\text { (n=128) }\end{array}$ & $\boldsymbol{P}$ \\
\hline $\begin{array}{l}\text { Mean age at the time of } \\
\text { the coronary angiography } \\
\text { (years } \pm S D \text { ) }\end{array}$ & $50.6 \pm 3.8$ & $45.8 \pm 4.2$ & $<0.001^{* *}$ \\
\hline Male/Female, $\mathrm{n}$ & $26 / 22$ & $67 / 61$ & $0.867^{*}$ \\
\hline $\mathrm{BMI}, \mathrm{kg} / \mathrm{m}^{2}$ & $27.2 \pm 3.7$ & $27.1 \pm 3.2$ & $0.787^{* *}$ \\
\hline Cigarette smoking, n (\%) & $18(38 \%)$ & $36(28 \%)$ & $0.272^{*}$ \\
\hline Total cholesterol, mg/dL & $191.0 \pm 41.6$ & $193.5 \pm 42.2$ & $0.690^{* *}$ \\
\hline LDL cholesterol, mg/dL & $109.5 \pm 35.4$ & $116.2 \pm 35.4$ & $0.246^{* *}$ \\
\hline Hemoglobin, mg/dL & $13.5 \pm 1.4$ & $13.2 \pm 1.5$ & $0.191^{* *}$ \\
\hline Glucose, mg/dL & $101.0 \pm 12.1$ & $98.2 \pm 11.1$ & $0.162^{* *}$ \\
\hline Creatinine, mg/dL & $0.80 \pm 0.15$ & $0.79 \pm 0.15$ & $0.136^{* *}$ \\
\hline
\end{tabular}

biological stress reaction (i.e., in the form of frequent autonomic nervous system-associated arousals from sleep and chronic sleep deprivation, that is, poor sleep efficiency), it could manifest as sympathetic over-activity and impairment of sympathetic baroreflex modulation, as previously observed in patients with obstructive sleep apnea syndrome (15).

The cyclic alternating pattern (CAP) is an endogenous rhythm present in NREM sleep characterized by a periodic EEG activity with sequences of transient electrocortical activations $(16,17)$. One of the proposed mechanism impairing sleep order in RLS is the 
increase of cyclic alterning pattern(CAP) rate, percentage of CAP time to NREM time, which is considered to be a marker of NREM sleep instability, reflecting a poor sleep quality (17-19).

During cyclic alternating pattern, the sympatho-vagal balance is shifted towards sympathetic prevalence. Therefore, it is possible that increased cardiovascular risk in RLS/PLMS is associated with cyclic alternating pattern alterations $(18,19)$.

One of the leading hypotheses for the pathogenesis of RLS and PLMS is that there is a dopaminergic deficit in these 2 related conditions (20). The strongest evidence for this hypothesis is the efficacy of dopaminergic therapy for both conditions $(21,22)$. Winkelman et al. (23) demonstrate a relationship between RLS and cardiovascular disease but not between RLS and hypertension. Winkelman et al. (24) suggested that the transient elevations in blood pressure associated with PLMS could cause cardiovascular disease by increasing the 24-hour blood pressure profile without producing changes in daytime blood pressure.

Oxidative stress could be an important factor in RLS pathogenesis (25). Baskol et al. (25) showed that increased levels of oxidant molecules such as advanced oxidation protein products, malondialdehyde, and decreased levels of antioxidant molecules such as thiol and nitric oxide suggest that patients with RLS are under oxidative stress. So they suggested that treatment for oxidative stress could be a future therapeutic option for RLS.

Previous studies have shown that small vessel disease, endothelial dysfunction, subclinical atherosclerosis, inflammation, and anatomic properties of coronary arteries are related to the occurrence of SCF (26-29). Current findings support the hypothesis that SCF may be part of systemic vascular disturbance. Our data suggested that a strong link between SCF and RLS, a common ethiological factor such as sympathetic overactivity should be further investigated.

Despite good prognosis of SCF patients, the subsequent progress is frequently characterized by remitting, relapsing anginal episodes and subsequently impairment in quality of life. Unfortunately, currently available anti-anginal agents are of limited clinical value. Adequate treatment of RLS may be a promising option for minimizing the risk of SCF or relieving symptoms of SCF. In a recent study with RLS found that pramipexole normalized the PLMS-related heart rate increase; the authors conclude that a reduction in PLMS index due to pramipexole is also likely accompanied by a decrease in BP (30). We speculated that, the effective treatment of RLS may improve endothelial dysfunction, decrease of cardiovascular risk during risk and may minimize SCF and associated symptoms.

\section{Study limitations}

The overall sample size of this study was small. We did not evaluate cyclic alternating pattern. Several relatively milder confounding factors, such as mild alcohol consumption, lower socioeconomic status, exercise, marital status, and exclusion of many potential confounders, might have had an impact on the results of our study, particularly in the setting of evaluation of the sleeping status.

\section{Conclusion}

Slow coronary flow and restless leg syndrome are both underestimated clinical conditions, yet resulting in considerable impairment in quality of life. Our study concluded that there is a strong link between SCF and RLS, which needs further investigation, especially supposing that adequate treatment of RLS could diminish risk of slow coronary flow.

\section{Conflict of interest: None declared.}

\section{Peer-review: Externally peer-reviewed.}

Authorship contributions: Concept - I.E., E.Ç.E.; Design - I.E., E.Ç.E., Y.T.; Supervision - I.E., M.A., Y.T.; Resources - I.E., E.Ç.E.; Material - H.T., H.D., M.T., M.E.K.; Data collection \&/or processing - H.T., H.D., M.T., M.E.K.; Analysis \&/or interpretation - I.E., E.Ç.E., H.T., H.D., M.T., M.E.K.; Literature search - I.E., E.Ç.E., Y.T., M.A.; Writing - I.E., E.C..E., Y.T., M.A.; Critical review - Y.T., M.A.

\section{References}

1. Smith JE, Tolson JM. Recognition, diagnosis, and treatment of restless legs syndrome. J Am Acad Nurse Pract 2008; 20: 396-401. [Crossref]

2. Ekbom K, Ulfberg J. Restless legs syndrome. J Int Med 2009; 266: 419-31. [Crossref]

3. Phillips B, Young T, Finn L, Asher K, Hening WA, Purvis C. Epidemiology of restless legs symptoms in adults. Arch Intern Med 2000; 160: 2137-41. [Crossref]

4. Winter AC, Berger K, Glynn RJ, Buring JE, Gaziano JM, Schürks M, et al. Vascular risk factors, cardiovascular disease, and restless legs syndrome in men. Am J Med 2013; 126: 228-35. [Crossref]

5. Tambe AA, Demany MA, Zimmerman HA, Mascarenhas E. Angina pectoris and slow flow velocity of dye in coronary arteries-a new angiographic finding. Am Heart J 1972; 84: 66-71. [Crossref]

6. Szentkirályi A, Völzke H, Hoffmann W, Happe S, Berger K. A time sequence analysis of the relationship between cardiovascular risk factors, vascular diseases and restless legs syndrome in the general population. J Sleep Res 2013; 22: 434-42. [Crossref]

7. Mangieri E, Macchiarelli G, Ciavolella M, Barilla F, Avella A, Martinotti $A$, et al. Slow coronary flow: clinical and histopathological features in patients with otherwise normal epicardial coronary arteries. Cathet Cardiovasc Diagn 1996; 37: 375-81. [Crossref]

8. Mosseri M, Yarom R, Gotsman MS, Hasin Y. Histologic evidence for small-vessel coronary artery disease in patients with angina pectoris and patent large coronary arteries. Circulation 1986; 74: 964-72. [Crossref]

9. Goddard AF, James MW, McIntyre AS, Scott BB. Guidelines for the management of iron deficiency anaemia. Gut 2011;60: 1309-16. [Crossref]

10. Just H. Coronary arteriography: current technique and standards of equipment. Med Prog Technol 1977; 5: 119-25.

11. Allen RP, Picchietti D, Hening WA, Trenkwalder C, Walters AS, Montplaisi J. Restless legs syndrome: diagnostic criteria, special considerations, and epidemiology. A report from the restless legs syndrome diagnosis and epidemiology workshop at the National Institutes of Health. Sleep Med 2003; 4: 101-19. [Crossref] 
12. Hening W, Walters AS, Allen RP, Montplaisir J, Myers A, FeriniStrambi L. Impact, diagnosis and treatment of restless legs syndrome (RLS) in a primary care population: The REST (RLS epidemiology, symptoms, and treatment) primary care study. Sleep Med 2004; 5: 237-46. [Crossref]

13. Lusardi P, Mugellini A, Preti P, Zoppi A, Derosa G, Fogari R. Effects of a restricted sleep regimen on ambulatory blood pressure monitoring in normotensive subjects. Am J Hypertens 1996; 9: 503-5. [Crossref]

14. Ogawa Y, Kanbayashi T, Saito Y, Takahashi Y, Kitajima T, Takahashi $K$, et al. Total sleep deprivation elevates blood pressure through arterial baroreflex resetting: a study with microneurographic technique. Sleep 2003; 26: 986-9.

15. Narkiewicz K, Pesek CA, Kato M, Phillips BG, Davison DE, Somers VK. Baroreflex control of sympathetic nerve activity and heart rate in obstructive sleep apnea. Hypertension 1998; 32: 1039-43. [Crossref]

16. Angriman $M$, Bruni 0 , Cortese $S$. Does restless legs syndrome increase cardiovascular risk in attention-deficit/hyperactivity disorder? Med Hypotheses 2013; 80: 39-42. [Crossref]

17. Bruni O, Novelli L, Miano S, Parrino L, Terzano MG, Ferri R. Cyclic alternating pattern: A window into pediatric sleep. Sleep Med 2010; 11: 628-36. [Crossref]

18. Ferri R, Manconi M, Aricò D, Sagrada C, Zucconi M, Bruni O, et al. Acute dopamine-agonist treatment in restless legs syndrome: effects on sleep architecture and NREM sleep instability. Sleep 2010; 33: 793-800.

19. Parrino L, Boselli M, Buccino GP, Spaggiari MC, Di Giovanni G, Terzano MG. The cyclic alternating pattern plays a gate-control on periodic limb movements during non-rapid eye movement sleep. J Clin Neurophysiol 1996; 13: 314-23. [Crossref]

20. Walters AS, Rye DB. Review of the relationship of restless legs syndrome and periodic limb movements in sleep to hypertension, heart disease, and stroke. Sleep 2009; 32: 589-97.

21. Walters AS, Ondo WG, Dreykluft $T$, Grunstein R, Lee D, Sethi K. Ropinirole is effective in the treatment of restless legs syndrome.
TREAT RLS 2: a 12-week, double-blind, randomized, parallel-group, placebo-controlled study. Mov Disord 2004; 19: 1414-23. [Crossref]

22. Winkelman JW, Sethi KD, Kushida CA, Becker PM, Koester J, Cappola JJ, et al. Efficacy and safety of pramipexole in restless legs syndrome. Neurology 2006; 67: 1034-9. [Crossref]

23. Winkelman JW, Finn L, Young T. Prevalence and correlates of restless legs syndrome symptoms in the Wisconsin Sleep Cohort. Sleep Med 2006; 7: 545-52. [Crossref]

24. Winkelman JW, Shahar E, Sharief I, Gottlieb DJ. Associations of restless legs syndrome and cardiovascular disease in the Sleep Heart Health Study. Neurology 2008; 70: 35-42. [Crossref]

25. Başkol G, Korkmaz S, Erdem F, Caniklioğlu A, Koçyiğit M, Aksu M. Assessment of nitric oxide, advanced oxidation protein products, malondialdehyde, and thiol levels in patients with restless legs syndrome. Sleep Med 2012; 13: 414-8. [Crossref]

26. Mangieri E, Macchiarelli G, Ciavolella M, Barilla F, Avella A, Martinotti $A$, et al. Slow coronary flow: clinical and histopathological features in patients with otherwise normal epicardial coronary arteries. Cathet Cardiovasc Diagn 1996; 37: 375-81. [Crossref]

27. Yazıcı M, Aksakal E, Demircan S, Şahin M, Sağkan O. Is slow coronary flow related with inflammation and procoagulant state? Anadolu Kardiyol Derg 2005; 5: 3-7.

28. Durakoğlugil ME, Kocaman SA, Çetin M, Kırbaş A, Çanga A, Erdoğan $T$, et al. Increased circulating soluble CD40 levels in patients with slow coronary flow phenomenon: an observational study. Anadolu Kardiyol Derg 2013; 13: 39-44.

29. Wang X, Geng LL, Nie SP. Coronary slow flow phenomenon: a local or systemic disease? Med Hypotheses 2010; 75: 334-7. [Crossref]

30. Manconi M, Ferri R, Zucconi M, Clemens S, Rundo F, Oldani A, et al. Effects of acute dopamine-agonist treatment in restless legs syndrome on heart rate variability during sleep. Sleep Med 2011; 12: 47-55. [Crossref] 
Copyright of Anatolian Journal of Cardiology / Anadolu Kardiyoloji Dergisi is the property of Aves Yayincilik Ltd. STI and its content may not be copied or emailed to multiple sites or posted to a listserv without the copyright holder's express written permission. However, users may print, download, or email articles for individual use. 